Article

\title{
Evaluation of 2-Mercaptobenzimidazole Derivatives as Corrosion Inhibitors for Mild Steel in Hydrochloric Acid
}

\author{
Hassane Lgaz ${ }^{1}$, Sheerin Masroor ${ }^{2}$, Maryam Chafiq ${ }^{3}$, Mohamed Damej ${ }^{4} \oplus$, Ameni Brahmia ${ }^{5}$, \\ Rachid Salghi ${ }^{3}$, Mohammed Benmessaoud ${ }^{4}$, Ismat H. Ali ${ }^{5}$ (D) Majed M. Alghamdi ${ }^{5}$, \\ Abdelkarim Chaouiki ${ }^{3}$ and Ill-Min Chung ${ }^{1, *}$ \\ 1 Department of Crop Science, College of Sanghur Life Science, Konkuk University, Seoul 05029, Korea; \\ hlgaz@konkuk.ac.kr \\ 2 Departement of Chemistry, Anugrah Narayan College, Patliputra University, Patna 800013, Bihar, India; \\ masroor.sheerin@gmail.com \\ 3 Laboratory of Applied Chemistry and Environment, ENSA, University Ibn Zohr, P.O. Box 1136, \\ Agadir 80000, Morocco; chafiq.maryam.1995@gmail.com (M.C.); r.salghi@uiz.ac.ma (R.S.); \\ abdelkarim.chaouiki@uit.ac.ma (A.C.) \\ 4 Energy, Materials and Sustainable Development Team, CERN2D, Higher School of Technology Salé, \\ Mohammed V University, Rabat 8007, Morocco; damejmohamed1979@gmail.com (M.D.); \\ benmessaoudmma@gmail.com (M.B.) \\ 5 Department of Chemistry, College of Science, King Khalid University, P.O. Box 9004, 61413 Abha, \\ Saudi Arabia; ameni.brahmia@yahoo.fr (A.B.); ismathassanali@gmail.com (I.H.A.); \\ mmalghamdi@kku.edu.sa (M.M.A.) \\ * Correspondence: imcim@konkuk.ac.kr; Tel.: +82-2450-3730
}

Received: 12 February 2020; Accepted: 6 March 2020; Published: 9 March 2020

\begin{abstract}
This research aimed to develop a better understanding of the corrosion inhibition of the mild steel in acidic medium by new organic molecules. For this purpose, two new compounds namely, 2,3-dihydrobenzo[4,5]imidazo[2,1-b]thiazole (2-BIT) and 3,4-dihydro-2H-benzo[4,5]imidazo [2,1-b]thiazole (3-BIT) were synthesized and evaluated for mild steel (MS) corrosion in HCl. Analyses were carried out using weight loss measurements, electrochemical techniques, and scanning electron microscope (SEM). The adsorption of inhibitors onto the steel surface follows the Langmuir adsorption model. Generally, results showed that the corrosion inhibition efficiency of the investigated molecules was found to increase with increased concentration of inhibitors. Electrochemical tests, i.e., electrochemical impedance spectroscopy (EIS) and potentiodynamic polarization (PDP) techniques, showed that the addition of our investigated inhibitors decreases the dissolution of the metal and generally act as mixed-type inhibitors. In addition, the influence of temperature (from 303 to $333 \mathrm{~K}$ ) on the corrosion inhibition was studied, and the results demonstrated that with an increase in temperature, the inhibition efficiency decrease. SEM results confirmed that the inhibition process is due to a protective film that prevents corrosion. Similarly, the results showed that the inhibitory efficiencies reach $93 \%$ at $5 \times 10^{-3} \mathrm{M}$ in the case of inhibitor 3-BIT. These results revealed that this compound could effectively control and reduce the corrosion rate of mild steel in the corrosion test solution.
\end{abstract}

Keywords: corrosion inhibition; 2-mercaptobenzimidazole; mild steel; $\mathrm{HCl}$; EIS; PDP

\section{Introduction}

Carbon steel is among the alloys, which are in ample use and best to study as a model for inhibition of corrosion. Hydrochloric and sulfuric acid are examples of mineral acids, which are 
extensively used as pickling acid, industrial acid cleaner, etc. [1]. The industrial acid cleaner and acid purification treatments are extremely aggressive and can lead to considerable corrosion of metals in these environments. One of the many ways to minimize metal corrosion is using inhibitors, which may be considered as the safest and cheapest option [2-6]. The inhibitors work at a proper concentration by acting at the interface of the exposed metal surface and aggressive media. Those compounds which are rich in heteroatoms such as nitrogen, oxygen, sulphur, and phosphorous, etc. and multiple bonds present in aromatic rings or carbon chains were widely employed as corrosion inhibitors in mineral acid solutions [7-10]. The lone pair in heteroatoms and the planarity of molecules are also essential characteristics that must be taken into account for the explanation of the adsorption of inhibitors molecules onto the metallic surface [11,12]. These inhibitors resist deterioration by hindering the chemically active deteriorating sites in two ways: (i) By establishing a protective layer or an insoluble complex, (ii) by its high ability to adsorb on the metallic surfaces. Other properties such as the aromaticity, electron density, functional groups and steric factors, nature of metal and corrosion environment also play an important role in inhibitive action [13]. The potency of a compound having sulfur as corrosion resistance for metals has been well reported $[13,14]$. Thioureas, along with its derivatives, are versatile compounds, able to inhibit the corrosion of steels, and are superior to many compounds usually employed for this purpose in acidic media $[15,16]$. Several studies concerned with the corrosion inhibition properties of 2-mercaptobenzimidazole (MBI) have already been undertaken [17-21]. Results emerging from these efforts demonstrate that MBI can act as a good corrosion inhibitor [22,23]. However, developing a highly effective inhibitor is still a great challenge due to the diversity of organic compounds. In this context, the structural uniqueness of MBI can make it an attractive starting point for the development of new effective corrosion inhibitors.

In the present work, the inhibition effect of synthesized 2-mercaptobenzimidazole derivatives, namely, 2,3-dihydrobenzo[4,5]imidazo[2,1-b]thiazole (2-BIT) and 3,4-dihydro-2H-benzo[4,5] imidazo[2,1-b]thiazole (3-BIT) was evaluated for MS corrosion in a $1.0 \mathrm{M} \mathrm{HCl}$ solution. This study was carried out through several techniques such as gravimetric measurements, electrochemical impedance spectroscopy (EIS), and potentiodynamic polarization (PDP). Along with this, corrosion inhibition effectiveness was investigated by the surface analysis method.

\section{Experimental Section}

\subsection{Synthesis of Benzimidazole Derivatives}

Products (2-BIT) and (3-BIT) (2,3-dihydrobenzo[4,5]imidazo [n,1-b]thiazole, $n=2$, or 3) were produced by the action of 2-mercaptobenzimidazol on 1, n-dibromoalcane in stoichiometric proportion in reflux ethanol for $6 \mathrm{~h}$ (Scheme 1). Products (2-BIT) and (3-BIT) were isolated with good yield (85\%) and were identified based on spectral data NMR $1 \mathrm{H}$ and NMR 13C.



Scheme 1. Synthesis procedure of investigated molecules. 
2-BIT: ${ }^{1} \mathrm{H}$ NMR (300 MHz, DMSO-d6) ( $\left.\delta, \mathrm{ppm}\right): 7.22$ (2H, Ar-H); 7.59 (2H, Ar-H); 3.96 (2H, S- $\left.\mathrm{CH}_{2}-\right)$ : $4.31\left(2 \mathrm{H}, \mathrm{N}-\mathrm{CH}_{2}-\right)$. 13C NMR (75 MHz, DMSO d6) ( $\left.8, \mathrm{ppm}\right): 110.0 ; 115.2 ; 123.0 ; 123.0$ (4CH, Benz), 134.2, 138.9 (2C, benz), 152.6 (C, Benzimi), $38.0\left(1 \mathrm{C}, \mathrm{CH}_{2}\right), 56.4\left(1 \mathrm{C}, \mathrm{CH}_{2}\right)$.

3-BIT: ${ }^{1} \mathrm{H}$ NMR (300 MHz, DMSO-d6) ( $\left.8, \mathrm{ppm}\right): 7.22$ (2H, Ar-H); 7.59 (2H, Ar-H); $2.17\left(2 \mathrm{H}, \mathrm{CH}_{2}\right)$; 2.93 (2H, S-CH $\left.2^{-}\right) ; 3.99$ (2H, N-CH $\left.2^{-}\right)$. 13C NMR (75 MHz, DMSO d6) (8, ppm): 110.0; 115.2; 123.0; 123.0 (4CH, Benz), 134.2, 138.9 (2C, Benz), 152.6 (C, Benzimi), 23.1 (1C, $\left.\mathrm{CH}_{2}\right), 24.8\left(1 \mathrm{C}, \mathrm{CH}_{2}\right), 48.5\left(1 \mathrm{C}, \mathrm{CH}_{2}\right)$.

\subsection{Test Specimens and Solutions Used}

The chemical distribution of elements present in mild steel with descending percentage is: $0.66 \mathrm{wt} \% \mathrm{Mn}, 0.36 \mathrm{wt} \% \mathrm{C}, 0.27 \mathrm{wt} \% \mathrm{Si}, 0.22 \mathrm{wt} \% \mathrm{Cu}, 0.21 \mathrm{wt} \% \mathrm{Cr}, 0.06 \mathrm{wt} \% \mathrm{Al}, 0.02 \mathrm{wt} \% \mathrm{~S}, 0.02 \mathrm{wt} \% \mathrm{Mo}$, $0.015 \mathrm{wt} \% \mathrm{P}$, and balance Fe.

The test solutions were made of $1.0 \mathrm{M} \mathrm{HCl}$ as aggressive blank while a stock solution of inhibitors with inhibitors concentration of $5 \times 10^{-3} \mathrm{M}$ was prepared in $1.0 \mathrm{M} \mathrm{HCl}$. A large range of concentrations was used for preliminary tests. Then, the range of concentrations was kept in between $5 \times 10^{-3} \mathrm{M}$ and $1 \times 10^{-4} \mathrm{M}$, which were obtained by diluting the stock solution with distilled water.

\subsection{Weight Loss Measurements}

The weight loss methods are the first approach to study the corrosion inhibition of steel in an electrolytic medium. In this way, gravimetric measurements were performed following the ASTM standard [24]. Multiple disk-shaped specimens with diameter $38 \mathrm{~mm}$ and thickness $3 \mathrm{~mm}$ with a hole of $8 \mathrm{~mm}$ diameter were prepared from obtained mild steel sheet for each test. The surface morphology of mild steel was prepared by employing emery papers of varying grades from 400-1600 and cleaned thoroughly.

Barely, MS specimens have been weighted with a precision balance and allowed to immerse in the solutions with different inhibitors concentrations at $303 \mathrm{~K}$. The specimens have been immersed in triplicate. After that, it was removed and cleaned correctly using distilled water and acetone and allowed to dry and finally weighted accurately again as previously signaled. The difference in weight loss was confirmed. The inhibitory performance was evaluated by monitoring the consequence of immersion time (1-70 h). Equation (1) is employed to calculate the corrosion rate values (in $\mathrm{mmy}^{-1}$ ).

$$
C=\frac{K \times W}{A \times t \times \rho}
$$

where $K$ represents a constant with the value of $8.76 \times 10^{4}$. W and $t$ are the weight loss in gram and the time of immersion in hours, respectively. The density of MS is $7.86 \mathrm{~g} \mathrm{~cm}^{-3}$ as per the ASTM G1-03 standard [25]. While A is the exposed area of the sample in $\mathrm{cm}^{2}$ [26].

\subsection{Electrochemical Techniques}

For all electrochemical tests, the measurements were performed by Volta Lab (Tacussel-Radiometer PGZ 100) potentiostat (Radiometer Analytical, Lyon, France) combined with Voltamaster software (Version 4.0, Radiometer Analytical, France). The cell is composed of a three-electrode assembly, which includes MS as a working electrode with the surface area of $1 \mathrm{~cm}^{2}$, platinum plate $(\mathrm{Pt})$ acts as an auxiliary electrode and a saturated calomel reference electrode. These measurements were performed using a cell that contains $80 \mathrm{~mL}$ of the solution. The mild steel is kept to its potential corrosion for $30 \mathrm{~min}$ before the commencement of all experiments. The potentiodynamic polarization measurements have been performed in the range from -800 to $-200 \mathrm{mV}$ of the corrosion potential with a scan rate of $0.5 \mathrm{mV} \mathrm{s}^{-1}$. For EIS measurements, the experiments have been conducted in the frequency range of $10 \mathrm{mHz}-100 \mathrm{kHz}$ and an AC amplitude of $10 \mathrm{mV}$. 


\subsection{Surface Study}

Morphologies of the MS surface immersed in $1.0 \mathrm{M} \mathrm{HCl}$ without and with the addition of inhibitors were assessed by using scanning electron microscopy (SEM). Samples were prepared as described above (weight loss section). SEM analysis was done using JEOL JSM-6480 LV (JEOL Ltd., Tokyo, Japan).

\section{Results and Discussion}

\subsection{Gravimetric Measurements}

The corrosion behavior of MS in $1.0 \mathrm{M} \mathrm{HCl}$ without and with different concentrations of inhibitors was studied in the temperature range of 303-333 K by applying the weight loss technique. The obtained results, such as corrosion rates $(W)$ and inhibition efficiencies $\left(\eta_{\mathrm{w}}\right)$ at each studied concentration, are given in Table 1. Equations (2) and (3) are applied to estimate the inhibition efficiency $\left(\eta_{\mathrm{w}}\right)$ and the surface coverage degree $(\theta)$ [27].

$$
\begin{aligned}
\eta_{w}(\%) & =\frac{C r-C r^{\circ}}{C r} \times 100 \\
\theta & =\frac{\eta_{w}(\%)}{100}
\end{aligned}
$$

where $C_{r}$ and $C_{r}{ }^{\circ}$ are corrosion rates before and after the addition of inhibitors in the aggressive media, respectively.

Table 1. Effect of 2-BIT and 3-BIT concentrations on corrosion data of mild steel in 1.0 M hydrochloric $(\mathrm{HCl})$ at $303 \mathrm{~K}$.

\begin{tabular}{cccc}
\hline Inhibitor & $\begin{array}{c}\text { Concentration } \\
(\mathbf{m o l} / \mathbf{L})\end{array}$ & $\begin{array}{c}W \\
\left(\mathbf{m g} / \mathbf{c m}^{\mathbf{2}} \times \mathbf{h}\right)\end{array}$ & $\eta_{W} \mathbf{( \% )}$ \\
\hline Blank & 1.0 & 1.135 & - \\
\hline \multirow{2}{*}{3 -BIT } & $5 \times 10^{-3}$ & 0.074 & 93 \\
\cline { 2 - 4 } & $1 \times 10^{-3}$ & 0.115 & 90 \\
\cline { 2 - 4 } & $5 \times 10^{-4}$ & 0.214 & 81 \\
\hline \multirow{2}{*}{ 2-BIT } & $1 \times 10^{-4}$ & 0.273 & 76 \\
\cline { 2 - 4 } & $5 \times 10^{-3}$ & 0.123 & 89 \\
\hline & $1 \times 10^{-3}$ & 0.262 & 77 \\
\hline & $5 \times 10^{-4}$ & 0.332 & 70 \\
\hline & $1 \times 10^{-4}$ & 0.473 & 58 \\
\hline
\end{tabular}

The concentration impact was thoroughly studied for both inhibitors separately employing the weight-loss method. It was observed that the corrosion rates are significantly lowered in the presence of inhibitors. According to Table 1, the inhibitor 3-BIT was found to be better in terms of inhibition efficiency. The lowering in the corrosion rates depends upon inhibitor 2-BIT and 3-BIT concentrations. The inhibitory effectiveness is raised by increasing the concentrations of inhibitor molecules. Moreover, at the concentration of $5 \times 10^{-3} \mathrm{M}$ at $303 \mathrm{~K}$, the maximum values of inhibition efficiency of 3-BIT (93.4\%) and 2-BIT (89.10\%) were observed. The increased inhibition efficiency for the compound 3-BIT is because several molecules are adsorbed on the exposed surface of MS at higher concentrations and thus leads to the appearance of film protection [28].

Furthermore, the ability of adsorption of the molecules on MS surface in the acidic solution can be associated with the presence of benzene ring, single $(\mathrm{C}-\mathrm{N})$, and a double bond $(\mathrm{C}=\mathrm{N})$ between carbon and nitrogen along with the C-S bond. It can be noted that our target inhibitors are the derivatives of 2-mercaptobenzimidazole which can be borrowed from benzimidazole with thiol group in the 2-position. The existence of these groups leads to blockage of active sites on the MS surface. Hence, 
the higher adsorption onto the MS surface can be predicted through charge transfer between certain delocalized $\pi$-electrons of the benzene ring and the empty $d$-orbital of the iron atom [29]. Further, the existence of heteroatoms such as nitrogen and sulfur in the synthesized molecules may also justify their use as suitable inhibitors of corrosion [30]. The difference in inhibition efficiency of both inhibitors maybe because both compounds have a different geometric length of the carbon chain. Inhibitor 3-BIT may be adsorbed more pronounced onto the metal surface due to the greater number of carbon atoms or $-\mathrm{CH}_{2}$ groups attached to aromatic ring and heteroatoms. This causes more adsorption over the surface of the metal and leading to more molecules to be adsorbed compared to inhibitor 2-BIT, which has a lesser number of $-\mathrm{CH}_{2}$ groups.

\subsubsection{Effect of Temperature}

In this analysis, the dissolution of MS in $1.0 \mathrm{M} \mathrm{HCl}$ was investigated in the temperature range of 303 to $333 \mathrm{~K}$ in the absence and presence of the synthesized inhibitor 3-BIT. The effect of temperature was thoroughly tested at each concentration for all temperatures studied to get the steadiness of the protective film formed over the metal surface. Results in Table 2 show that the inhibition efficiency decreases with rising temperature. The highest inhibition efficiency with value of $93 \%$ was achieved for concentration $5 \times 10^{-3} \mathrm{M}$ at temperature $303 \mathrm{~K}$, which drops to $78 \%$ on raising the temperature to $333 \mathrm{~K}$, keeping the same concentration of inhibitor 2-BIT. The same trend was followed at all concentrations studied at different temperatures. This may be due to the desorption of adsorbed molecules from the metal surface with increasing temperature [31].

Table 2. The temperature effect toward inhibition efficiency and corrosion rate of 3-BIT.

\begin{tabular}{|c|c|c|c|c|c|c|c|c|}
\hline $\begin{array}{l}\text { Concentration } \\
(\mathrm{mol} / \mathrm{L})\end{array}$ & \multicolumn{2}{|c|}{$303 \mathrm{~K}$} & \multicolumn{2}{|c|}{$313 \mathrm{~K}$} & \multicolumn{2}{|c|}{$323 \mathrm{~K}$} & \multicolumn{2}{|c|}{$333 \mathrm{~K}$} \\
\hline $5 \times 10^{-3}$ & 0.074 & 93 & 0.147 & 89 & 0.383 & 81 & 0.553 & 78 \\
\hline $1 \times 10^{-3}$ & 0.115 & 90 & 0.276 & 80 & 0.473 & 76 & 0.726 & 71 \\
\hline $1 \times 10^{-4}$ & 0.273 & 76 & 0.385 & 73 & 0.599 & 70 & 0.858 & 66 \\
\hline
\end{tabular}

\subsubsection{Effect of Immersion Time}

To evaluate the stability of the behavior of inhibitor 3-BIT, the impact of immersion time was also studied at $303 \mathrm{~K}$ for all concentrations, and results are presented in Figure 1. As predicted from the graph, the highest inhibition efficiency was deduced from optimum concentration $\left(5 \times 10^{-3} \mathrm{M}\right)$. In addition, there was a gradual increase in efficiency with an increase in immersion time up to a specific period ( 10-15 h) and became constant. The establishment of a protective film on the MS surface might explain this result, which protects the metal surface over a more extended test period of approx. $70 \mathrm{~h}$. 




Figure 1. The inhibition efficiencies obtained for mild steel (MS) in $1.0 \mathrm{M} \mathrm{HCl}$ with the addition of various concentrations of 3-BIT at $303 \mathrm{~K}$.

\subsection{Electrochemical Impedance Spectroscopy (EIS)}

To procure further inquiry related to the mechanism for inhibiting corrosion of MS, electrochemical impedance spectroscopy experiments have been performed in uninhibited and inhibited solutions for both inhibitors at temperature $303 \mathrm{~K}$. The diagrams of Nyquist and Bode obtained for MS in $1.0 \mathrm{M} \mathrm{HCl}$ are shown in Figure 2. The smoothness of semicircles (Nyquist) as obtained slightly deviated from the standard EIS theory. These imperfections of the capacitive loop are resultant of the unevenness of the metal surface, heterogeneity, and dispersion in frequency [32]. It was observed that the capacitive loop for $1.0 \mathrm{M} \mathrm{HCl}$ alone had the smallest diameter. The diameter of loops expands with increasing inhibitors concentration, implying the increase of the impedance (Nyquist curves). These findings indicate that the tested compounds have good inhibitory behavior due to their adsorption on the metal surface at higher concentrations. Bode and phase angle plots were also analyzed and are represented in Figure 2. Distinctly, the value of the phase angle heightened considerably as the inhibitor concentration increased. It was marked that for both used inhibitors, the values of phase angle were always higher in comparison to the blank but lower than $-90^{\circ}$ that is indicative of the nonideal capacitor. Furthermore, the spectra obtained showed single depressed semicircles and a single one time constant. This is intriguing of the evidence that only one circumstance was prevailing for MS dissolution for metal/aggressive solution interface through the charge transfer process [33].

Electrochemical parameters can be obtained by fitting EIS results with an electrical equivalent circuit. By the cause of nonideal behavior of metal surface, constant phase element (CPE) is used instead of a pure capacitor to evaluate data obtained from the impedance. In the present study, all the EIS data were analyzed using the $[R s+(\mathrm{CPE} / R p)]$ equivalent circuit, where $R s$ is the solution resistance, $\mathrm{Rp}$ is the polarization resistance, and $\mathrm{CPE}$ is the constant phase element. The reason for using polarization resistance $(R p)$ instead of charge transfer resistance is previously discussed in detail [34]. The value of CPE can be extracted from the given formula [35]:

$$
Z_{C P E}=\frac{1}{Q(j \omega)^{n}}
$$


Here, terms " $Q$ " represents CPE magnitude, " $\omega$ " signifies angular frequency, " $j$ " $=-1$ is the imaginary number, and " $n$ " is related to phase shift which can be correlated with the unevenness of the metal surface. Most importantly, the CPE is also extensible for adjusting impedance spectra. $C_{d l}$ is determined using the equation below [36].

$$
C_{d l}=\sqrt[n]{Q \times R_{p}^{1-n}}
$$

Table 3 lists the entire electrochemical impedance parameters in addition to the inhibition efficiency $\eta_{E I S}(\%)$. The effectiveness of corrosion inhibition can be estimated by the given equation [37]:

$$
\eta_{E I S(\%)}=\left[\frac{R_{p(i n h)-R_{p}}}{R_{p(i n h)}}\right] \times 100
$$

where the values of $R_{\mathrm{p}}$ and $R_{\mathrm{p}}$ (inh) reveal the polarization resistances of the MS specimen in $1.0 \mathrm{M}$ $\mathrm{HCl}$ without and with the addition of the inhibitor, respectively, the obtained values showed that with the addition of both inhibitors 2-BIT and 3-BIT, the polarization resistance values are continuously enhanced and increase with increasing concentration of organic compounds tested, while the values of $C_{d l}$ showed a significant decrease. This is reasonably due to the modification of the metal/electrolyte interface by a sharp rise of the double electric layer thickness because of the adsorption of a significant quantity of molecules on the MS surface.


Figure 2. Nyquist curves and Bode and phase angle diagrams of $\mathrm{MS}$ in $1.0 \mathrm{M} \mathrm{HCl}$ without and with different concentrations of $(\mathbf{A}, \mathbf{B}) 3$-BIT and $(\mathbf{C}, \mathbf{D})$ 2-BIT at $303 \mathrm{~K}$. 
Table 3. Electrochemical impedance spectroscopy (EIS) results recorded for MS in the acidic medium at several concentrations of 3-BIT and 2-BIT at $303 \mathrm{~K}$.

\begin{tabular}{|c|c|c|c|c|c|c|c|}
\hline Inhibitor & $\begin{array}{c}\text { Concentration } \\
(\mathrm{mol} / \mathrm{L})\end{array}$ & $\begin{array}{c}R_{p} \\
\left(\Omega \times \mathrm{cm}^{2}\right)\end{array}$ & $n$ & $\begin{array}{c}Q \times 10^{-4} \\
\left(S^{n} \Omega^{-1} \mathbf{c m}^{-2}\right)\end{array}$ & $\begin{array}{c}C_{d l} \\
\left(\mu \mathrm{F} / \mathrm{cm}^{2}\right)\end{array}$ & $\eta_{\text {EIS }}(\%)$ & $\theta$ \\
\hline Blank & 1.0 & 29 & 0.89 & 1.761 & 91 & - & - \\
\hline \multirow{4}{*}{ 3-BIT } & $5 \times 10^{-3}$ & 453 & 0.80 & 0.398 & 14 & 93 & 0.93 \\
\hline & $1 \times 10^{-3}$ & 266 & 0.76 & 0.589 & 15 & 89 & 0.89 \\
\hline & $5 \times 10^{-4}$ & 162 & 0.78 & 0.712 & 20 & 82 & 0.82 \\
\hline & $1 \times 10^{-4}$ & 115 & 0.81 & 1.085 & 38 & 74 & 0.74 \\
\hline \multirow{4}{*}{ 2-BIT } & $5 \times 10^{-3}$ & 248 & 0.78 & 0.583 & 17 & 88 & 0.88 \\
\hline & $1 \times 10^{-3}$ & 125 & 0.79 & 0.659 & 18 & 76 & 0.76 \\
\hline & $5 \times 10^{-4}$ & 94 & 0.80 & 0.896 & 27 & 69 & 0.69 \\
\hline & $1 \times 10^{-4}$ & 69 & 0.82 & 1.146 & 39 & 57 & 0.57 \\
\hline
\end{tabular}

\subsection{Polarization Curves}

The polarization curves of the MS in $1.0 \mathrm{M} \mathrm{HCl}$ with and without inhibitors at $303 \mathrm{~K}$ are graphically represented in Figure 3. Numerical values of electrochemical parameters such as corrosion potential $\left(E_{\text {corr }}\right)$, corrosion current density $\left(i_{\text {corr }}\right)$, and Tafel cathodic $\left(\beta_{\mathrm{c}}\right)$ and anodic $\left(\beta_{\mathrm{a}}\right)$ slopes, which are determined by the Tafel extrapolation method are summarized in Table 4 . Moreover, the effectiveness of inhibition can be determined by the following formula [38]:

$$
\eta_{P D P}(\%)=\left[1-\frac{i_{\text {corr }}}{i_{\text {corr }}^{\circ}}\right] \times 100
$$

where, $i_{\text {corr }}$ and $i^{\circ}$ corr are the corrosion current density in the $\mathrm{HCl}$ media with and without the addition of inhibitor, respectively.

Table 4. Potentiodynamic polarization (PDP) results obtained for $\mathrm{MS}$ in $1.0 \mathrm{M} \mathrm{HCl}$ at different concentrations of 3-BIT and 2-BIT along with their corresponding inhibition efficiency.

\begin{tabular}{|c|c|c|c|c|c|c|c|}
\hline Inhibitor & $\begin{array}{c}\text { Concentration } \\
(\mathrm{mol} / \mathrm{L})\end{array}$ & $\begin{array}{c}-E_{\text {corr }} \\
\text { (mV/SCE) }\end{array}$ & 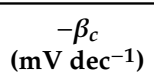 & $\begin{array}{c}\beta_{a} \\
\left(\mathrm{mV} \operatorname{dec}^{-1}\right)\end{array}$ & $\begin{array}{c}i_{\text {corr }} \\
\left(\mu \mathrm{A} \mathrm{cm}^{-2}\right)\end{array}$ & $\eta_{P D P}(\%)$ & $\theta$ \\
\hline Blank & 1.0 & 496 & 150 & 132 & 564 & - & - \\
\hline \multirow{4}{*}{ 3-BIT } & $5 \times 10^{-3}$ & 505 & 170 & 89 & 41 & 92 & 0.92 \\
\hline & $1 \times 10^{-3}$ & 513 & 172 & 98 & 69 & 87 & 0.87 \\
\hline & $5 \times 10^{-4}$ & 524 & 167 & 98 & 99 & 82 & 0.82 \\
\hline & $1 \times 10^{-4}$ & 504 & 177 & 96 & 146 & 74 & 0.74 \\
\hline \multirow{4}{*}{ 2-BIT } & $5 \times 10^{-3}$ & 498 & 163 & 97 & 62 & 89 & 0.89 \\
\hline & $1 \times 10^{-3}$ & 496 & 168 & 99 & 134 & 76 & 0.76 \\
\hline & $5 \times 10^{-4}$ & 503 & 162 & 93 & 169 & 70 & 0.70 \\
\hline & $1 \times 10^{-4}$ & 494 & 154 & 95 & 233 & 58 & 0.58 \\
\hline
\end{tabular}

As observed from Figure 3, when inhibitors were added to the aggressive solution, both cathodic and anodic reactions have been decreased, which became more pronounced at higher concentrations of inhibitors 3-BIT and 2-BIT. Moreover, there is no remarkable shift in corrosion potential to more anodic or more cathodic potentials in comparison with the corrosion potential observed in blank solution. In addition, we notice from Figure 3 that the cathodic current-potential curves significantly reduced compared to the blank and all curves result in the same trend of line shape which states that the inhibitor is unable to affect the hydrogen release mechanism and that this reaction is controlled by activation [39]. This leads to the fact that the real interaction process is kept the same while the surface 
available for hydrogen ions $\left(\mathrm{H}^{+}\right)$is significantly decreased [40]. This explained the inhibitory action of tested compounds, which can be linked to their adsorption, and formation of a protective film on the surface of MS. The presence of both inhibitors only decreases the value of $i_{\text {corr }}$ but is unable to modify the other parameters of the polarization behavior. The obtained values of $i_{\text {corr }}$ have been employed to estimate the inhibition efficacy. As can be seen from Table 4, the inhibition efficiencies increased with the addition of both inhibitors' concentration compared to the aggressive solution. In our comparative study, inhibitor 3-BIT gives higher corrosion inhibition efficiencies compared to 2-BIT and is consistent with values obtained from the gravimetric method and electrochemical impedance spectroscopy.


Figure 3. Potentiodynamic polarization curves of $\mathrm{MS}$ in $1.0 \mathrm{M} \mathrm{HCl}$ without and with different concentrations of 3-BIT (a) and 2-BIT (b) at $303 \mathrm{~K}$.

\subsection{Adsorption Isotherm}

In this part, different types of adsorption isotherms, namely, Langmuir, Freundlich, Temkin, and Frumkin, are tested to give more insight about the corrosion inhibition mechanism, and thus providing details on the interaction of the inhibitor molecules with the metal surface. In this study, the best description of the adsorption behavior of tested corrosion inhibitors can be explained by the Langmuir adsorption isotherm; which is given by Equation (8) [41]:

$$
\frac{C}{\theta}=\frac{1}{K_{a d s}}+C
$$


In the given equation, $K_{\mathrm{ads}}$ is the equilibrium constant of the adsorption process, $C$ is the concentration of the used inhibitor, and $\theta$ is the degree of surface coverage.

It is given that the inhibition efficiency of corrosion inhibitor is $\eta \%=\theta \times 100$, where $\theta$ is the covering degree of the inhibiting protective film. It can be noted that the value of $\theta$ for different concentrations of inhibitors 3-BIT and 2-BIT in $1.0 \mathrm{M} \mathrm{HCl}$ solution was calculated from the gravimetric measurements. The given equation can be used for the calculation of $\Delta G^{\circ}$ ads (free energy of adsorption) which is related to $K_{\mathrm{ads}}$ :

$$
\Delta G_{a d s}^{\circ}=-R T \operatorname{Ln}\left(K_{\mathrm{ads}} \times 55.5\right)
$$

where 55.5 is the numerical value of the molar concentration of $\mathrm{H}_{2} \mathrm{O}$ in $\mathrm{mol} / \mathrm{L}$ [42]. The plots of $C / \theta$ versus the concentration of both inhibitors are traced with slopes close to 1 , which is typical of Langmuir's adsorption isotherm (Figure 4). The value of regression constant, i.e., $R^{2}$ for both inhibitors, is 0.999 giving more evidence that the adsorption of tested compounds obeys the Langmuir isotherm.

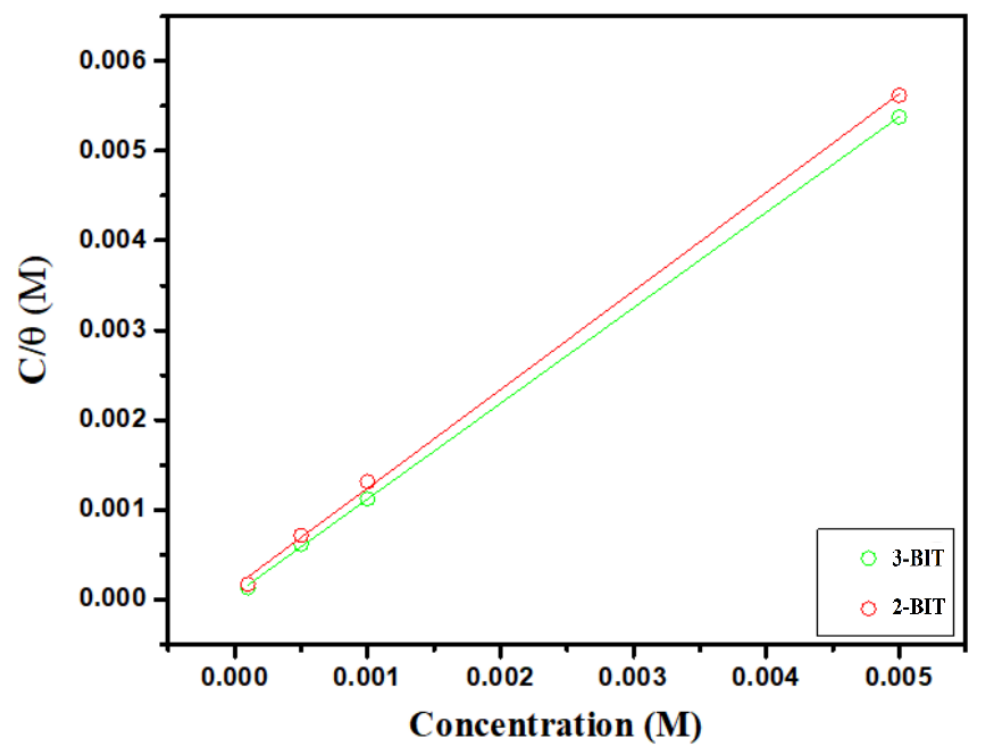

Figure 4. Langmuir adsorption isotherm of inhibitors 3-BIT and 2-BIT on the surface of the MS in $1.0 \mathrm{M}$ $\mathrm{HCl}$ medium derived from weight loss measurement.

The high value of $K_{\text {ads }}$ suggests tenacious interactions between the inhibitor molecule and the MS surface. Further, inhibitor 3-BIT having a height value of $K_{\text {ads }}(58798 \mathrm{~L} / \mathrm{mol})$ indicates better adsorption of this inhibitor and hence better corrosion inhibition efficiency. Concerning the free energy of adsorption, the negative values obtained for inhibitors 3-BIT $(-37.76 \mathrm{KJ} / \mathrm{mol})$ and 2-BIT $(-36.93 \mathrm{KJ} / \mathrm{mol})$ show spontaneity of the adsorption process [43]. It is always considered that the value of $\Delta \mathrm{G}_{\text {ads }}$ greater than $-20 \mathrm{~kJ} / \mathrm{mol}$ confirms physisorption, whereas, when the values of $\Delta G_{a d s}$ is less than $-40 \mathrm{~kJ} / \mathrm{mol}$, it corresponds to chemisorption interactions. Nevertheless, the values of $\Delta G_{a d s}$ between -20 and $-40 \mathrm{~kJ} \mathrm{~mol}^{-1}$ indicates a complex adsorption process. According to our study, it can be observed that the $\Delta G_{a d s}$ adsorption values of the 3-BIT and 2-BIT inhibitors are -37.76 and $-36.93 \mathrm{~kJ} \mathrm{~mol}^{-1}$, respectively, indicating that the adsorption of these molecules is a mixed type (both physisorption and chemisorption) [44].

\subsection{Surface Characterization}

To investigate the surface morphology of MS and the ability of tested compounds to inhibit its corrosion, the scanning electron microscope was employed. Figure 5 shows SEM images of the MS surface after $72 \mathrm{~h}$ of immersion in a $1.0 \mathrm{M} \mathrm{HCl}$ solution with and without 3-BIT at a concentration of $5 \times 10^{-3} \mathrm{M}$. Figure 5 clearly shows that the MS is attacked in the absence of inhibitor. However, in its presence, we can see on the image of the steel surface after $72 \mathrm{~h}$ of immersion in a $1.0 \mathrm{M} \mathrm{HCl}$ 
medium that the corrosion of the mild steel surface is markedly reduced, and a smooth surface was obtained. This demonstrates that it is inhibited by the creation of a stable and tight deposit that limits the electrolyte's access to the steel surface.

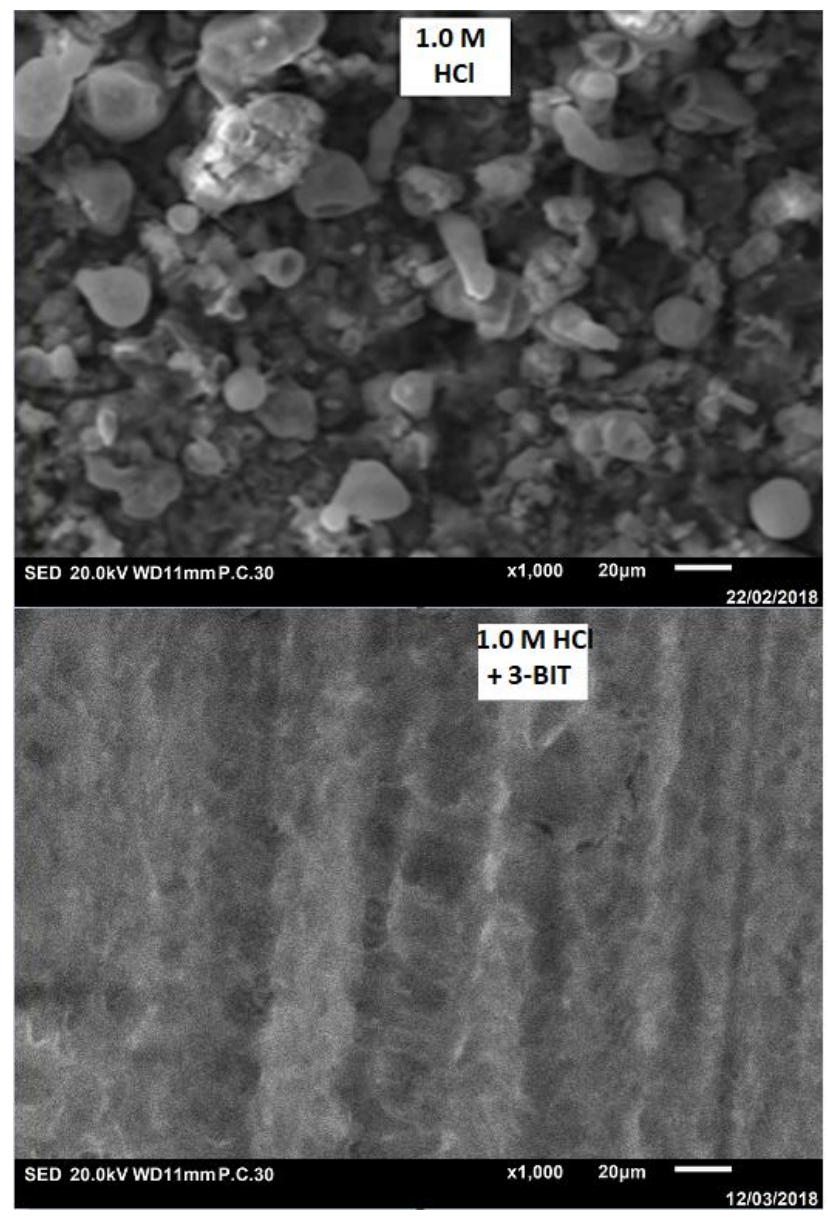

Figure 5. Surface morphology by SEM for MS immersed in $1.0 \mathrm{M} \mathrm{HCl}$ in the absence and presence of 3-BIT.

\section{Conclusions}

Anti-corrosion performance of two new sulfur-containing compounds 3-BIT and 2-BIT was analyzed using different experimental techniques for mild steel in $\mathrm{HCl}$ acid. The studied compounds showed good corrosion inhibition performances for MS in the $\mathrm{HCl}$ medium and their activity increased with increasing inhibitor concentration, while efficacy decreased with increasing temperature. Molecule 3-BIT showed a high corrosion inhibition property of $\mathrm{MS}$ in $1.0 \mathrm{M} \mathrm{HCl}$ in the temperature range of 303 to $333 \mathrm{~K}$. The EIS study found that the addition of the inhibitor compounds increased both the resistance of polarization and the inhibition efficiency. The PDP measurements confirmed the mixed-type action mode of inhibitors. The adsorption isotherm study showed that adsorption of both inhibitors obeyed the Langmuir adsorption isotherm. The analysis of the MS morphology of the metal surface confirmed the remarkable adsorption tendency of tested compounds over the metal surface. Further efforts will be made soon to understand better interactions between investigated inhibitors and metal surface employing theoretical methods.

Author Contributions: H.L., M.C., and S.M., investigation, formal analysis, writing—original draft; M.D., A.C., and M.B., investigation; A.B., I.H.A., and M.M.A., investigation, resources, project administration, writing-review and editing; I.-M.C. and R.S., conceptualization, methodology, validation, supervision, writing-review and editing. All authors have read and agreed to the published version of the manuscript. 
Funding: This research was funded by the Deanship of Scientific Research at King Khalid University, grant number R.G.P.1/150/40.

Acknowledgments: The authors extend their appreciation to the Deanship of Scientific Research at King Khalid University for funding this work through the research groups program under grant number R.G.P.1/150/40.

Conflicts of Interest: The authors of this manuscript have no conflict of interest to declare.

\section{References}

1. Aljourani, J.; Golozar, M.A.; Raeissi, K. The inhibition of carbon steel corrosion in hydrochloric and sulfuric acid media using some benzimidazole derivatives. Mater. Chem. Phys. 2010, 121, 320-325. [CrossRef]

2. Lindsay, R.; Kokalj, A. Corrosion Inhibition. Metals 2018, 8, 821. [CrossRef]

3. Ehsani, A.; Nasrollahzadeh, M.; Mahjani, M.G.; Moshrefi, R.; Mostaanzadeh, H. Electrochemical and quantum chemical investigation of inhibitory of 1,4- $\mathrm{Ph}(\mathrm{OX}) 2(\mathrm{Ts}) 2$ on corrosion of 1005 aluminum alloy in acidic medium. J. Ind. Eng. Chem. 2014, 20, 4363-4370. [CrossRef]

4. Dehghani, A.; Bahlakeh, G.; Ramezanzadeh, B.; Ramezanzadeh, M. Detailed macro-/micro-scale exploration of the excellent active corrosion inhibition of a novel environmentally friendly green inhibitor for carbon steel in acidic environments. J. Taiwan Inst. Chem. Eng. 2019, 100, 239-261. [CrossRef]

5. Asadi, N.; Ramezanzadeh, M.; Bahlakeh, G.; Ramezanzadeh, B. Utilizing Lemon Balm extract as an effective green corrosion inhibitor for mild steel in $1 \mathrm{M} \mathrm{HCl}$ solution: A detailed experimental, molecular dynamics, Monte Carlo and quantum mechanics study. J. Taiwan Inst. Chem. Eng. 2019, 95, 252-272. [CrossRef]

6. Bahlakeh, G.; Ramezanzadeh, B.; Dehghani, A.; Ramezanzadeh, M. Novel cost-effective and high-performance green inhibitor based on aqueous Peganum harmala seed extract for mild steel corrosion in $\mathrm{HCl}$ solution: Detailed experimental and electronic/atomic level computational explorations. J. Mol. Liq. 2019, 283, $174-195$. [CrossRef]

7. Verma, C.; Ebenso, E.; Bahadur, I.; Obot, I.; Quraishi, M. 5-(Phenylthio)-3H-pyrrole-4-carbonitriles as effective corrosion inhibitors for mild steel in $1 \mathrm{M} \mathrm{HCl}$ : Experimental and theoretical investigation. J. Mol. Liq. 2015, 212, 209-218. [CrossRef]

8. Verma, C.; Quraishi, M.; Singh, A. 2-Amino-5-nitro-4, 6-diarylcyclohex-1-ene-1, 3, 3-tricarbonitriles as new and effective corrosion inhibitors for mild steel in $1 \mathrm{M} \mathrm{HCl}$ : Experimental and theoretical studies. J. Mol. Liq. 2015, 212, 804-812. [CrossRef]

9. Daoud, D.; Douadi, T.; Hamani, H.; Chafaa, S.; Al-Noaimi, M. Corrosion inhibition of mild steel by two new S-heterocyclic compounds in $1 \mathrm{M} \mathrm{HCl}$ : Experimental and computational study. Corros. Sci. 2015, 94, $21-37$. [CrossRef]

10. Kubba, R.M.; Alag, A.S. Experimental and Theoretical Evaluation of new Quinazolinone Derivative as Organic Corrosion Inhibitor for Carbon Steel in 1M HCl Solution. Int. J. Sci. Res. IJSR6 2017, 6, 1832-1842.

11. Bentiss, F.; Lagrenee, M.; Traisnel, M.; Hornez, J. The corrosion inhibition of mild steel in acidic media by a new triazole derivative. Corros. Sci. 1999, 41, 789-803. [CrossRef]

12. Baskar, R.; Kesavan, D.; Gopiraman, M.; Subramanian, K. Corrosion inhibition of mild steel in 1.0M hydrochloric acid medium by new photo-cross-linkable polymers. Prog. Org. Coat. 2014, 77, 836-844.

13. Verma, C.; Olasunkanmi, L.O.; Ebenso, E.E.; Quraishi, M.A. Substituents effect on corrosion inhibition performance of organic compounds in aggressive ionic solutions: A review. J. Mol. Liq. 2018, 251, 100-118. [CrossRef]

14. Fouda, A.S.; Attia, A.A.; Negm, A. Some thiophene derivatives as corrosion inhibitors for carbon steel in hydrochloric acid solution. J Met. 2014, 2014, 1-15.

15. Awad, M.K. Semiempirical investigation of the inhibition efficiency of thiourea derivatives as corrosion inhibitors. J. Electroanal. Chem. 2004, 567, 219-225. [CrossRef]

16. Torres, V.; Rayol, V.; Magalhães, M.; Viana, G.; Aguiar, L.; Machado, S.; Orofino, H.; D’Elia, E. Study of thioureas derivatives synthesized from a green route as corrosion inhibitors for mild steel in $\mathrm{HCl}$ solution. Corros. Sci. 2014, 79, 108-118. [CrossRef]

17. El-Hajjaji, F.; Belghiti, M.E.; Hammouti, B.; Jodeh, S.; Hamed, O.; Lgaz, H.; Salghi, R. Adsorption and corrosion inhibition effect of 2-mercaptobenzimidazole (surfactant) on a carbon steel surface in an acidic medium: Experimental and monte carlo simulations. Port. Electrochimica Acta 2018, 36, 197-212. [CrossRef] 
18. Popova, A.; Christov, M.; Raicheva, S.; Sokolova, E. Adsorption and inhibitive properties of benzimidazole derivatives in acid mild steel corrosion. Corros. Sci. 2004, 46, 1333-1350. [CrossRef]

19. Zhang, G.A.; Hou, X.M.; Hou, B.S.; Liu, H.F. Benzimidazole derivatives as novel inhibitors for the corrosion of mild steel in acidic solution: Experimental and theoretical studies. J. Mol. Liq. 2019, 278, 413-427. [CrossRef]

20. Morales-Gil, P.; Walczak, M.S.; Cottis, R.A.; Romero, J.M.; Lindsay, R. Corrosion inhibitor binding in an acidic medium: Interaction of 2-mercaptobenizmidazole with carbon-steel in hydrochloric acid. Corros. Sci. 2014, 85, 109-114. [CrossRef]

21. Wang, L. Evaluation of 2-mercaptobenzimidazole as corrosion inhibitor for mild steel in phosphoric acid. Corros. Sci. 2001, 43, 2281-2289. [CrossRef]

22. Mahdavian, M.; Ashhari, S. Corrosion inhibition performance of 2-mercaptobenzimidazole and 2-mercaptobenzoxazole compounds for protection of mild steel in hydrochloric acid solution. Electrochimica Acta 2010, 55, 1720-1724. [CrossRef]

23. Aljourani, J.; Raeissi, K.; Golozar, M.A. Benzimidazole and its derivatives as corrosion inhibitors for mild steel in $1 \mathrm{M} \mathrm{HCl}$ solution. Corros. Sci. 2009, 51, 1836-1843. [CrossRef]

24. Scully, J.; Baboian, R. Standard Practice for Laboratory Immersion Corrosion Testing of Metals; ASTM: Philadelphia, PA, USA, 1995; p. 110.

25. ASTM, E. 647: Standard test method for measurement of fatigue crack growth rates. Annu. Book ASTM Stand. 2011, 3, 591-630.

26. Eduok, U.M.; Khaled, M.M. Corrosion protection of non-alloyed AIAI 316L concrete steel metal grade in aqueous H2SO4: Electroanalytical and surface analyses with Metiamide. Constr. Build. Mater. 2014, 68, 285-290. [CrossRef]

27. Singh, A.; Ansari, K.R.; Chauhan, D.S.; Quraishi, M.A.; Lgaz, H.; Chung, I.-M. Comprehensive investigation of steel corrosion inhibition at macro/micro level by ecofriendly green corrosion inhibitor in $15 \% \mathrm{HCl}$ medium. J. Colloid Interface Sci. 2020, 560, 225-236. [CrossRef]

28. Singh, D.K.; Kumar, S.; Udayabhanu, G.; John, R.P. 4 (N, N-dimethylamino) benzaldehyde nicotinic hydrazone as corrosion inhibitor for mild steel in $1 \mathrm{M} \mathrm{HCl}$ solution: An experimental and theoretical study. J. Mol. Liq. 2016, 216, 738-746. [CrossRef]

29. Gopi, D.; Sherif, E.-S.M.; Surendiran, M.; Jothi, M.; Kumaradhas, P.; Kavitha, L. Experimental and theoretical investigations on the inhibition of mild steel corrosion in the ground water medium using newly synthesised bipodal and tripodal imidazole derivatives. Mater. Chem. Phys. 2014, 147, 572-582. [CrossRef]

30. Guadalupe, H.J.; Garcia-Ochoa, E.; Maldonado-Rivas, P.J.; Cruz, J.; Pandiyan, T. A combined electrochemical and theoretical study of N, N'-bis (benzimidazole-2yl-ethyl)-1, 2-diaminoethane as a new corrosion inhibitor for carbon steel surface. J. Electroanal. Chem. 2011, 655, 164-172. [CrossRef]

31. Dehri, İ.; Özcan, M. The effect of temperature on the corrosion of mild steel in acidic media in the presence of some sulphur-containing organic compounds. Mater. Chem. Phys. 2006, 98, 316-323. [CrossRef]

32. Zhang, D.; Tang, Y.; Qi, S.; Dong, D.; Cang, H.; Lu, G. The inhibition performance of long-chain alkyl-substituted benzimidazole derivatives for corrosion of mild steel in $\mathrm{HCl}$. Corros. Sci. 2016, 102, 517-522. [CrossRef]

33. Zhou, J.; Chen, S.; Zhang, L.; Feng, Y.; Zhai, H. Studies of protection of self-assembled films by 2-mercapto-5-methyl-1, 3, 4-thiadiazole on iron surface in $0.1 \mathrm{M} \mathrm{H} 2 \mathrm{SO} 4$ solutions. J. Electroanal. Chem. 2008, 612, 257-268. [CrossRef]

34. Solmaz, R.; Kardaş, G.; Çulha, M.; Yazıcı, B.; Erbil, M. Investigation of adsorption and inhibitive effect of 2-mercaptothiazoline on corrosion of mild steel in hydrochloric acid media. Electrochimica Acta 2008, 53, 5941-5952. [CrossRef]

35. Li, X.; Deng, S.; Lin, T.; Xie, X.; Du, G. 2-Mercaptopyrimidine as an effective inhibitor for the corrosion of cold rolled steel in HNO3 solution. Corros. Sci. 2017, 118, 202-216. [CrossRef]

36. Cao, Z.; Tang, Y.; Cang, H.; Xu, J.; Lu, G.; Jing, W. Novel benzimidazole derivatives as corrosion inhibitors of mild steel in the acidic media. Part II: Theoretical studies. Corros. Sci. 2014, 83, 292-298. [CrossRef]

37. Chaouiki, A.; Lgaz, H.; Chung, I.-M.; Ali, I.; Gaonkar, S.L.; Bhat, K.; Salghi, R.; Oudda, H.; Khan, M. Understanding corrosion inhibition of mild steel in acid medium by new benzonitriles: Insights from experimental and computational studies. J. Mol. Liq. 2018, 266, 603-616. [CrossRef]

38. Li, L.; Zhang, X.; Lei, J.; He, J.; Zhang, S.; Pan, F. Adsorption and corrosion inhibition of Osmanthus fragran leaves extract on carbon steel. Corros. Sci. 2012, 63, 82-90. [CrossRef] 
39. Obot, I.; Obi-Egbedi, N.; Eseola, A. Anticorrosion potential of 2-mesityl-1H-imidazo [4,5-f][1,10] phenanthroline on mild steel in sulfuric acid solution: Experimental and theoretical study. Ind. Eng. Chem. Res. 2011, 50, 2098-2110. [CrossRef]

40. Quraishi, M. Electrochemical and theoretical investigation of triazole derivatives on corrosion inhibition behavior of copper in hydrochloric acid medium. Corros. Sci. 2013, 70, 161-169.

41. Saha, S.K.; Dutta, A.; Ghosh, P.; Sukul, D.; Banerjee, P. Novel Schiff-base molecules as efficient corrosion inhibitors for mild steel surface in $1 \mathrm{M} \mathrm{HCl}$ medium: Experimental and theoretical approach. Phys. Chem. Chem. Phys. 2016, 18, 17898-17911. [CrossRef]

42. El Aoufir, Y.; Aslam, R.; Lazrak, F.; Marzouki, R.; Kaya, S.; Skal, S.; Ghanimi, A.; Ali, I.H.; Guenbour, A.; Lgaz, H.; et al. The effect of the alkyl chain length on corrosion inhibition performances of 1,2,4-triazole-based compounds for mild steel in $1.0 \mathrm{M} \mathrm{HCl}$ : Insights from experimental and theoretical studies. J. Mol. Liq. 2020, 303, 112631. [CrossRef]

43. Yadav, D.K.; Quraishi, M. Electrochemical investigation of substituted pyranopyrazoles adsorption on mild steel in acid solution. Ind. Eng. Chem. Res. 2012, 51, 8194-8210. [CrossRef]

44. Lgaz, H.; Saha, S.K.; Chaouiki, A.; Bhat, K.S.; Salghi, R.; Shubhalaxmi; Banerjee, P.; Ali, I.H.; Khan, M.I.; Chung, I.-M. Exploring the potential role of pyrazoline derivatives in corrosion inhibition of mild steel in hydrochloric acid solution: Insights from experimental and computational studies. Constr. Build. Mater. 2020, 233, 117320. [CrossRef]

(C) 2020 by the authors. Licensee MDPI, Basel, Switzerland. This article is an open access article distributed under the terms and conditions of the Creative Commons Attribution (CC BY) license (http://creativecommons.org/licenses/by/4.0/). 